\title{
Math1 Gene Transfer Generates New Cochlear Hair Cells in Mature Guinea Pigs In Vivo
}

\author{
Kohei Kawamoto, ${ }^{1,2}$ Shin-Ichi Ishimoto, ${ }^{1,3}$ Ryosei Minoda, ${ }^{1,4}$ Douglas E. Brough, ${ }^{5}$ and Yehoash Raphael ${ }^{1}$ \\ ${ }^{1}$ Kresge Hearing Research Institute, Department of Otolaryngology, The University of Michigan, Ann Arbor, Michigan 48109-0648, ${ }^{2}$ Department of \\ Otolaryngology, Kansai Medical University, Moriguchi, Osaka, 570-8506, Japan, ${ }^{3}$ Department of Otolaryngology, Tokyo University, Bunkyo-ku, Tokyo, \\ 113-8655, Japan, ${ }^{4}$ Department of Otolaryngology-Head and Neck Surgery, Kumamoto University School of Medicine, Kumamoto, 860-8556, Japan, and \\ ${ }^{5}$ GenVec Inc., Gaithersburg, Maryland 20878
}

\begin{abstract}
Hair cell loss in the mammalian cochlea is irreversible and results in permanent hearing loss. Math1, the basic helix-loop-helix transcription factor homolog of the Drosophila atonal gene, is a positive regulator of hair cell differentiation during cochlear development. Developing hair cells express Math1, and nonsensory cells do not. We set out to determine the outcome of overexpression of Math1 in nonsensory cells of the cochlea on the phenotype of these cells. We demonstrate that in vivo inoculation of adenovirus with the Math1 gene insert into the endolymph of the mature guinea pig cochlea results in Mathl overexpression in nonsensory cochlear cells, as evident from the presence of Math1 protein in supporting cells of the organ of Corti and in adjacent nonsensory epithelial cells. Math1 overexpression leads to the appearance of immature hair cells in the organ of Corti and new hair cells adjacent to the organ of Corti in the interdental cell, inner sulcus, and Hensen cell regions. Axons are extended from the bundle of auditory nerve toward some of the new hair cells, suggesting that the new cells attract auditory neurons. We conclude that nonsensory cells in the mature cochlea retain the competence to generate new hair cells after overexpression of Math1 in vivo and that Math1 is necessary and sufficient to direct hair cell differentiation in these mature nonsensory cells.
\end{abstract}

Key words: hair cell; guinea pig; regeneration; Math1; gene therapy; adenovirus; supporting cell

\section{Introduction}

The auditory sensory epithelium in the inner ear, the organ of Corti, is an epithelial mosaic made of hair cells and supporting cells. Hair cell loss may result from aging, excessive exposure to loud stimuli, bacterial and viral infections, or ototoxic drugs. Cellular renewal on the basis of stem (basal) cell proliferation is a hallmark of most epithelial tissues. However, the organ of Corti lacks basal cells, and the terminally differentiated auditory hair cells are not replaced once lost (Hawkins, 1973). Thus, cochlear hair cell loss leads to permanent hearing impairment, the most common sensory disorder in humans.

On the basis of data obtained in avian inner ears, differentiated supporting cells are able to change their phenotype and become new hair cells (Corwin and Cotanche, 1988; Ryals and Rubel, 1988). Supporting cells can generate new hair cells by transdifferentiation (Raphael, 1992; Stone and Cotanche, 1994) or by conversion of the phenotype without cell division (Adler and Raphael, 1996; Roberson et al., 1996). Supporting cells are

Received Feb. 21, 2003; revised Feb. 21, 2003; accepted March 13, 2003.

This work was supported by GenVec and National Institutes of Health/National Institute on Deafness and Other Communication Disorders Grant R01 DC01634. We thank Tama Hasson, Jane Johnson, and Huda Zoghbi for reagents. We thank Christopher Zurenko and James Beals for their help in preparation of the figures. We thank Sally Camper, Tom Glaser, Peter Hitchcock, Donna Martin, and John Middlebrooks for valuable discussions and helpful comments on this manuscript.

Correspondence should be addressed to Dr. Yehoash Raphael, Kresge Hearing Research Institute, 1150 West Medical Center Drive, Ann Arbor, MI 48109-0648. E-mail: yoash@umich.edu.

Copyright $\odot 2003$ Society for Neuroscience $\quad$ 0270-6474/03/234395-06\$15.00/0 therefore an attractive target for interventions designed to produce new hair cells.

The discovery of developmental genes that encode hair cell differentiation facilitates the design of interventions to promote generation of new hair cells in cochleae with hair cell loss. Basic helix-loop-helix (bHLH) transcription factors regulate the development of a variety of systems in vertebrates and invertebrates (Hutcheson and Vetter, 2001; Vetter and Brown, 2001). Mechanoreceptors, including hair cells, depend on bHLH genes for their differentiation (Bermingham et al., 1999; Leonard et al., 2002). Expression of the bHLH transcription factor Math1, the mouse homolog of the Drosophila gene atonal, is essential for generating hair cells (Bermingham et al., 1999; Zine et al., 2001; Chen et al., 2002). After maturation of hair cells, the expression of Math1 is downregulated (Zheng et al., 2000). Overexpression of Math1 in cultures of immature rat cochleae results in the production of ectopic hair cells derived from nonsensory epithelial precursors (Zheng and Gao, 2000). The outcome of Math1 overexpression in the mature inner ear has not been determined. We set out to determine the influence of Mathl overexpression on the phenotype of supporting cells in the mature cochlea in vivo. We demonstrate that, after viral-mediated gene transfer of Mathl, nonsensory epithelial cells in the mature cochlea express the transgene and retain the competence to generate new hair cells in vivo. We also show that some of the new hair cells generated after the Math1 gene transfer attract auditory neurons. 


\section{Materials and Methods}

Adenovirus vectors. The Math $1 \mathrm{cDNA}$ used for the construct was obtained from Huda Zoghbi (Baylor College of Medicine, Houston, TX). The three vectors, Ad.Math1.11D, Ad.LacZ, and adenovirus with no gene insert, were based on human adenovirus serotype 5 with E1, E3, and E4 regions deleted, as described previously (Brough et al., 1996). Expression of the transgene insert in each of these vectors was driven by the human cytomegalovirus promoter.

Animals and inoculation surgery. We used young adult guinea pigs (4-5 weeks of age) weighing 350-500 gm at the beginning of the experiment. Inoculation surgery and composition of artificial endolymph were essentially as described by Ishimoto et al. (2002), except that the viral vector (or control) solutions were inoculated using an electromechanical infusion pump (Harvard Apparatus, Holliston, MA). The inoculation procedure was performed once (for every animal), serving as a tool for inducing lesion and delivering Ad.Math1.11D or control solutions. Animal care and use were in accordance with National Institutes of Health and institutional guidelines. Animals used to detect transgene expression were killed $4 \mathrm{~d}$ after inoculation ( $n=6$ for Math $1 ; n=5$ for $\beta$-galactosidase). Animals used to assess for new hair cells were examined using scanning electron microscopy or myosin VIIa antibody. These animals were killed $30 \mathrm{~d}$ ( $n=5$ for scanning electron microscopy; $n=4$ for myosin VIIa) or $60 \mathrm{~d}$ ( $n=9$ for scanning electron microscopy; $n=5$ for myosin VIIa) after the inoculation. Neurofilament staining was performed on normal animals, as well as those killed $60 \mathrm{~d}$ after Ad.Math1.11D or control vector inoculation. At least three animals were used for each control group.

Scanning electron microscopy. Guinea pigs were anesthetized and transcardially perfused with saline, followed by $2 \%$ glutaraldehyde in cacodylate buffer $(0.15 \mathrm{M})$. Cochleae were processed for scanning electron microscopy using the osmium thiocarbohydrazide method (Osborne and Comis, 1991). Samples were then dehydrated, and the critical point was dried with $\mathrm{CO}_{2}$ in a SamDri-790 (Tousimis, Rockville, MD), mounted on stubs using silver paste, and photographed digitally using a Philips XL30 Field-Emission Gun scanning electron microscope (FEI, Hillsboro, OR).

Immunocytochemistry. Whole mounts of the auditory sensory epithelium and surrounding tissues were used to localize Math1, myosin VIIa, and neurofilament. We fixed cochleae in $4 \%$ paraformaldehyde in phosphate buffer, $\mathrm{pH} 7.4$, removed the spiral ligament, stria vascularis, and tectorial membrane, and then permeabilized the tissue with $0.3 \%$ Triton $\mathrm{X}-100$ in PBS for $10 \mathrm{~min}$. Nonspecific binding of secondary antibodies was blocked with 5\% BSA in PBS for 20 min. Tissues were reacted with primary antibody, rinsed, and incubated with the secondary antibody. To perform double staining of neurofilaments and myosin VIIa, we used FITC secondary antibody for neurofilaments and tetramethylrhodamine isothiocyanate (TRITC) fluorescence for myosin VIIa. To double stain for F-actin, we used FITC-conjugated phalloidin (1:400; Molecular Probes, Junction City, OR). Specimens were mounted on glass slides using CrystalMount (Biomeda, Foster City, CA). Cryosections of the organ of Corti and surrounding cochlear epithelium were used to localize $\beta$-galactosidase and Math1. Cryosections were obtained as described by Ishimoto et al. (2002) and immuno-stained as described above.

Primary antibodies were a rabbit polyclonal anti-myosin VIIa antibody (a gift from Tama Hasson, University of California San Diego, San Diego, CA) diluted 1:200 in PBS with $0.1 \%$ BSA for $1 \mathrm{hr}$, a rabbit polyclonal anti-Math1 (a gift from Jane Johnson, The University of Texas Southwestern Medical Center at Dallas, Dallas, TX) diluted 1:200, a monoclonal antibody against neurofilament $200 \mathrm{kDa}$ (Sigma, St. Louis, MO) diluted 1:200 in PBS for $1 \mathrm{hr}$, and a rabbit polyclonal against $\beta$-galactosidase (Chemicon, Temecula, CA) used as described by Ishimoto et al. (2002). Secondary antibodies were TRITC-conjugated goat anti-rabbit or anti-mouse (Jackson ImmunoResearch, West Grove, PA) diluted 1:200 in PBS.

Specimens were examined and recorded using a Leica DMRB epifluorescence microscope (Leica, Eaton, PA) using 40 and 100× oil ob- jectives and a CCD Cooled SPOT-RT digital camera (Diagnostic Instruments, Sterling Heights, MI).

\section{Results}

\section{Nonsensory cochlear cells express transgenes}

To insert genes into nonsensory cells in the cochlea, we used adenovirus vectors. We constructed an adenoviral vector designated Ad.Math1.11D, with the Math1 cDNA insert, as described previously (Brough et al., 1996). Ad.Math1.11D or controls (artificial endolymph, an adenovirus vector with no gene insert or reporter gene vector designated Ad.LacZ) were surgically injected into the cochlear endolymph of the left inner ear in mature guinea pigs. Experimental animals had not undergone any treatment before the inoculation. The injected volume $(5 \mu \mathrm{l})$ was larger than the total volume of endolymph in guinea pigs (Thorne et al., 1999) and therefore resulted in a mechanical trauma, injuring some hair cells and causing degeneration of others (Fig. 1a-c). The inoculation procedure was performed once (for every animal), serving as a tool for inducing lesion and delivering Ad.Math1.11D or control solutions. The lesion caused by the inoculation was similar in Math1-treated animals (Fig. 1b,c) and controls (Fig. 2e) and appeared milder in areas more remote from the site of inoculation. The lesion was most severe at the site of inoculation, where most hair cells were eliminated and the Hensen cells area appeared hypertrophied (Fig. $3 e, i$ ).

To detect reporter gene expression, we killed the animals $4 \mathrm{~d}$ after Ad.LacZ inoculation and analyzed cochlear cryosections. At the site of inoculation, Ad.LacZ transgene expression was found in several cell types in the epithelium, including supporting cells of the organ of Corti and adjacent epithelial cells that reside lateral or medial to the organ of Corti (Fig. 1a). These epithelial cells included Hensen cells and cells in the inner sulcus and interdental cell regions (Figs. 1 $a, 4$ ).

We assessed the extent of Math1 transgene expression using a Math1-specific antibody in cochleae processed $4 \mathrm{~d}$ after Ad.Math1.11D inoculation. Numerous cells in the third turn of Ad.Math1.11D-inoculated animals were Math1 positive in the organ of Corti and in adjacent regions, including Hensen cells, inner sulcus areas (Fig. 1b), and the interdental cell area (data not shown). Most Math1-positive cells were within the normal boundaries of the organ of Corti (Fig. 1b,d). To better localize Math1-positive cells and distinguish hair cells from supporting cells or scars (sites of missing hair cells), cochleae were double stained with FITC phalloidin (Fig. $1 b, c$ ). We determined that most Math1-positive cells were nonsensory cells (Fig. 1c).

We used cryosections to localize Math1-positive cells in the fourth (apical) and second cochlear turns, flanking the site of inoculation. We determined that the extent of lesion decreased in areas distant from the inoculation site, with most hair cells surviving (Fig. 1d,e). Many nonsensory epithelial cells were Math1 positive, whereas most hair cells were Math1 negative (Fig. 1d,e). Control-inoculated cochleae were Math1 negative (Fig. $1 f, g$ ), demonstrating the absence of Math1 expression in the mature cochlea. These data demonstrate robust and efficient expression of Math1 in nonsensory cells of the auditory epithelium after Ad.Math1.11D inoculation into the third-turn endolymph.

\section{New and immature hair cells in the cochlea}

To assess the surface morphology of the cochlear epithelium, we performed scanning electron microscopy analysis in the inner ears obtained from animals killed 30 or $60 \mathrm{~d}$ after the inoculation. After Ad.Math1.11D inoculation, we observed hair cells adjacent to the organ of Corti, in which hair cells are typically absent (Fig. 

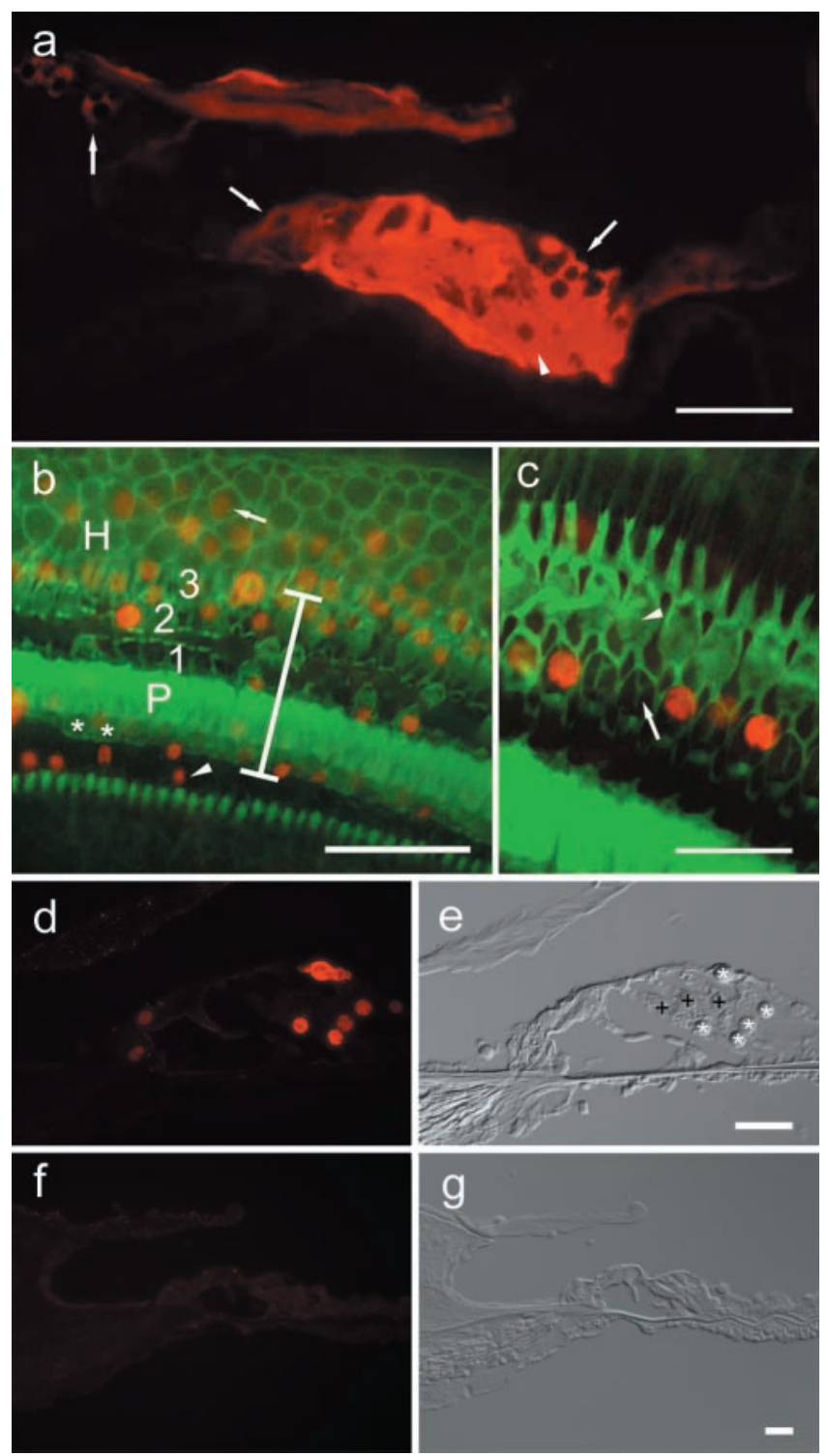

Figure 1. Epifluorescence of $\beta$-galactosidase and Math1 in the cochlear epithelium $4 \mathrm{~d}$ after Ad.Math1.11D inoculation. $a$, A cryosection showing $\beta$-galactosidase immunoreactivity in interdental (left arrow), inner sulcus (middle arrow), Hensen (right arrow), and supporting cells of the organ of Corti (arrowhead) in a cryosection of the third cochlear turn. $b$, A whole mount showing that Math1-positive nuclei (red) are in the inner sulcus (arrowhead), organ of Corti (vertical bar spans organ of Corti area; asterisk depicts inner hair cells; P depicts pillar cells; 1, 2, and 3 are first, second, and third row outer hair cells, respectively), and in the Hensen cell area $(H)$ in which Math1-positive nuclei (arrow) are observed $>30 \mu \mathrm{m}$ outside the organ of Corti. Phalloidin staining (green) identifies surviving hair cells and sites of hair cell loss. c, Remaining hair cells adjacent to the inoculation site (phalloidin stain, green) are Math1 negative (arrowhead points to third row, outer hair cells). Some of the nonsensory cells that replaced lost hair cells (arrow in second row, outer hair cell area) are Math1 positive (red). d, e, Cryosection ( $d$ ) of second turn of Ad.Math1.11D-inoculated organ of Corti showing Math1 immunoreactivity in nuclei of nonsensory cells $\left(^{*}\right)$. Outer hair cells $(+)$ and several other cell types are negative. Nomarski optics image of same cryosection (e) identified cells shown in d. $f, g$, Cryosection of second-turn auditory epithelium of Ad.LacZ-inoculated cochlea. Math1 immunoreactivity is negative $(f)$. Nomarski optics image of same cryosection $(g)$ identifies cells. Scale bars: $a, b, 50$ $\mu \mathrm{m} ; c, d-g, 25 \mu \mathrm{m}$.

3) (for schematic, see Fig. 4). The most remote area that contained ectopic hair cells was the interdental cell region (Fig. $3 a-c$ ). The morphology of some ectopic hair cells appeared similar to normal mature hair cells (Fig. 3c). Typically, approximately onethird of the ectopic hair cells exhibited a well differentiated sur- face morphology. Within the organ of Corti, we detected hair cells with an immature appearance (Fig. $3 d$ ). No immaturelooking hair cells were observed in any of the control-inoculated cochleae (data not shown).

In most Ad.Math1.11D-inoculated cochleae, the number of hair cells with an immature appearance was between 25 and 50 . However, we could not reliably distinguish between old (preexisting) and new hair cells within the boundaries of the organ of Corti. In the inner sulcus area, which resides immediately medial to the organ of Corti (Fig. 4), we observed some immature hair cells with short stereocilia (Fig. $3 e, f$ ) and some hair cells with longer stereocilia (Fig. 3g,h). Ectopic hair cells were also found in the Hensen cell area, immediately lateral to the organ of Corti (Figs. 3i,j, 4).

All Ad.Math1.11D-inoculated animals assessed with scanning electron microscopy exhibited new hair cells $(n=14)$. In five animals killed $60 \mathrm{~d}$ after the inoculation, the number of ectopic cells varied from 2 to 10 per cochlea. In four animals killed $30 \mathrm{~d}$ after Ad.Math1.11D inoculation, we observed two to nine ectopic cells per cochlea. Cells observed to have features typical of hair cells in ectopic locations were not counted if there was any doubt as to their phenotypic identification. Cochleae receiving control inoculations did not exhibit any ectopic hair cells (data not shown; $n=12$ ). These data demonstrate that nonsensory cells in the mature mammalian cochlea retain the competence to generate hair cells after viral-mediated overexpression of Math1.

\section{New hair cells express myosin VIIa}

We also characterized the phenotype of new hair cells with antibodies against myosin VIIa, a hair cell-specific marker (Hasson et al., 1995). In normal (noninoculated) ears (Fig. 2f), myosin VIIa antibody stains inner and outer hair cells (Hasson et al., 1995). In all of the cochleae that were inoculated with Ad.Math1.11D and processed for myosin VIIa immunocytochemistry after $60 \mathrm{~d}$, myosin VIIa-positive cells were found in the organ of Corti and adjacent areas, including the inner sulcus (data not shown), interdental cell (Fig. 2a), and Hensen cell areas (Fig. 2b). The number of myosin VIIa-positive cells in ectopic sites was similar to that seen in scanning electron microscopy preparations of Ad.Math1.11D-inoculated ears ranging from 4 to 10 per cochlea. Expression of Myo7a in these cells also identified them as hair cells, consistent with the scanning electron microscopy images.

\section{New hair cells attract neurons}

To assess for the presence of axons in the vicinity of new ectopic hair cells, we double stained control-inoculated and Ad.Math1.11D-treated cochleae (time point, $60 \mathrm{~d}$ ) with antibodies to myosin VIIa and neurofilament. Assessment of doublestained cochlear whole mounts revealed that neurofilament staining within the cochlear epithelium was restricted to the organ of Corti in noninoculated cochleae (Fig. $2 f$ ) and controlinoculated cochleae (Fig. 2e), with no axons in the regions of Hensen cells, inner sulcus, and interdental cells. In contrast, in Ad.Math1.11D-treated tissues, long and slender neurofilamentstained fibers extended over $50 \mu \mathrm{m}$ from the organ of Corti toward some myosin VIIa-labeled ectopic hair cells in the interdental cell area (Fig. 2c) and toward the Hensen cell area (Fig. 2d), suggesting that axons grow toward newly formed ectopic hair cells in the cochlea. Nerve processes have been shown to remain in the area of the traumatized organ of Corti long after hair cells are lost (Strominger et al., 1995). Our data suggest that, when given a new target (a new hair cell), some of these axons will extend and grow toward it. 


\section{Discussion}

Plasticity and the potential for repair are commonly found in developing tissues. In explants of developing rat cochleae, Math1 was sufficient to produce extra hair cells via phenotypic conversion of nonsensory cells (Zheng and Gao, 2000). Plasticity and the ability to repair injuries during development do not usually persist into adulthood. However, our in vivo data indicate that nonsensory cochlear cells maintain their competence to become new hair cells in mature animals, and that Math1 is a potent transcription factor that induces the nonsensory cochlear cells to generate new hair cells. Thus, Math1 appears sufficient to activate the cellular program, leading mature differentiated cells to recapitulate development.

Using immunocytochemistry with Math1-specific antibodies, we demonstrate that mature hair cells downregulate Math1 expression. This finding is in agreement with reverse transcriptionPCR data showing downregulation of Math1 in the mature rat cochlea (Zheng et al., 2000) and with the transient developmental expression seen with other bHLH transcription factor genes, such as Math5 (Brown et al., 1998). These data demonstrate that Math1-positive cells in the inoculated cochleae express the transgene rather than the endogenous Math1. Therefore, the results implicate transgenic Math1 expression in nonsensory cells in signaling the generation of new hair cells. A causative relationship between Math1 overexpression and new hair cell production is also demonstrated by the findings that all Math1-treated ears displayed new hair cells, whereas no new hair cells were found in any of the control-treated ears.

Regenerated hair cells within the organ of Corti are likely to contribute more than ectopic cells toward recovery of hearing. Nevertheless, the potential functional contribution of ectopic hair cells should not be overlooked. Ectopic hair cells in the inner sulcus are adjacent to inner hair cells. Similar to inner hair cells, the neighboring ectopic cells are situated on a part of the basilar membrane that is not free to vibrate (Slepecky, 1996). The luminal fluid movements that generate receptor potentials by deflecting stereocilia of inner hair cells (the primary auditory hair cells) may also stimulate ectopic hair cells. Thus, provided that ectopic cells differentiate and receive innervation, they may contribute to cochlear function.

Most Math1-positive cells that were identified in cochlea $4 \mathrm{~d}$ after Math1 inoculation were within the normal boundaries of the organ of Corti. Surface analysis 2 months later revealed numerous cells with surface morphology resembling immature hair cells within the organ of Corti. Although we cannot unequivocally identify these cells as new hair cells, the absence of such immature cells in control-treated cochleae suggest that they are regenerated hair cells induced by Math1 overexpression. Future experiments using Math1 overexpression in cochleae that are completely depleted of their original hair cells may help identify new hair cells within the organ of Corti.
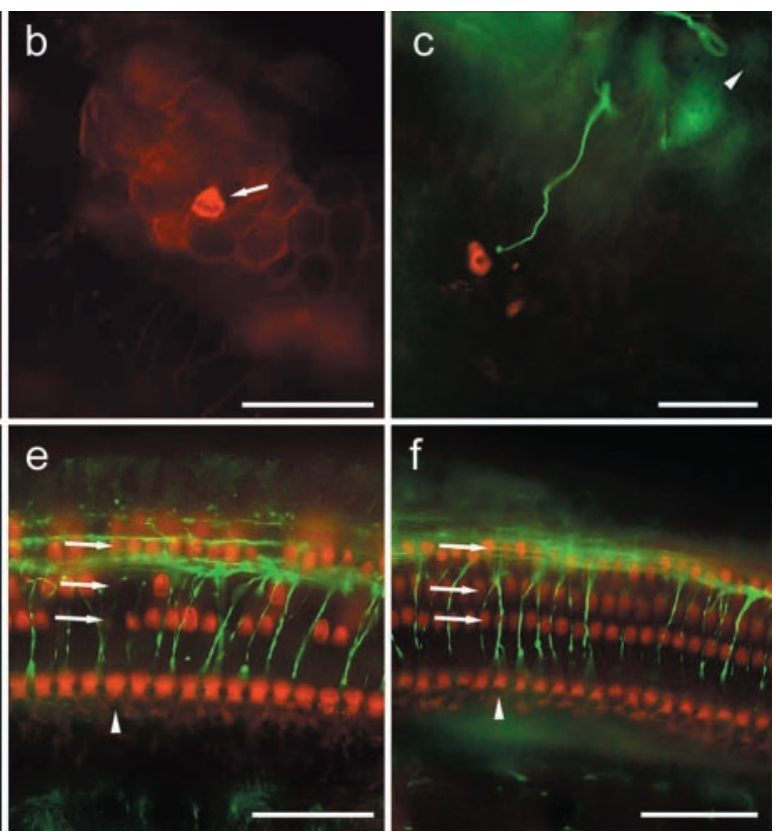

Figure 2. Myosin VIla and neurofilaments in Ad.Math1.11D-treated and normal cochleae. a, Myosin VIla-positive ectopic hair (arrows) among interdental cells. Inner hair cells (arrowheads) mark the medial border of the organ of Corti. $b, A$ myosin (arrow) among Hensen cells. c, An ectopic myosin Vlla-positive hair cell (red) in the interdental cell region. An normal (noninoculated) cochlea. Myosin VIla (red) is in inner (arrowhead) and outer (arrows) hair cells. Micrographs are oriented with medial (modiolar) side down. Scale bars, $25 \mu \mathrm{m}$.

In Math1 null mice, the auditory sensory primodrium and supporting cells develop normally, but hair cells are not generated (Bermingham et al., 1999; Chen et al., 2002). Similarly, mice with mutations in $\mathrm{Brn}-3 \mathrm{c}$, a likely postranscriptional target of Math1 (Vetter and Brown, 2001; Leonard et al., 2002), fail to develop cochlear hair cells (Erkman et al., 1996). Mutations in the human homolog POU4F3 cause hereditary deafness (Vahava et al., 1998). Together with these previous reports, our data suggest that Math1 is necessary and sufficient to direct hair cell differentiation in the cochlea and may act as a master switch for hair cell differentiation via transcriptional activation of $P O U 4 F 3$ and potentially other genes.

The bundles of stereocilia on most ectopic hair cells did not reach a level of maturity seen on normal hair cells 2 months after Ad.Math1.11D inoculation. It is possible that a longer period of time is required for bundle maturation. However, it is likely that the extracellular environment and cell-cell communication in ectopic locations cannot support the formation of completely normal bundles. As such, ectopic hair cells may be experimentally useful for elucidating the requirements for normal hair cell differentiation.

In birds, nonsensory cells of the auditory epithelium spontaneously generate new hair cells after experimentally induced trauma (Corwin and Cotanche, 1988; Ryals and Rubel, 1988). Chick hair cell regeneration can occur via a mitotic (transdifferentiation) or nonmitotic (conversion) mechanism (Adler and Raphael, 1996; Roberson et al., 1996; Stone and Rubel, 2000). It is unclear whether the present results using Math1 overexpression involve generation of new hair cells via transdifferentiation or conversion. Newly generated hair cells in the avian basilar papilla often appear in pairs (Raphael, 1992). Although we cannot rule 

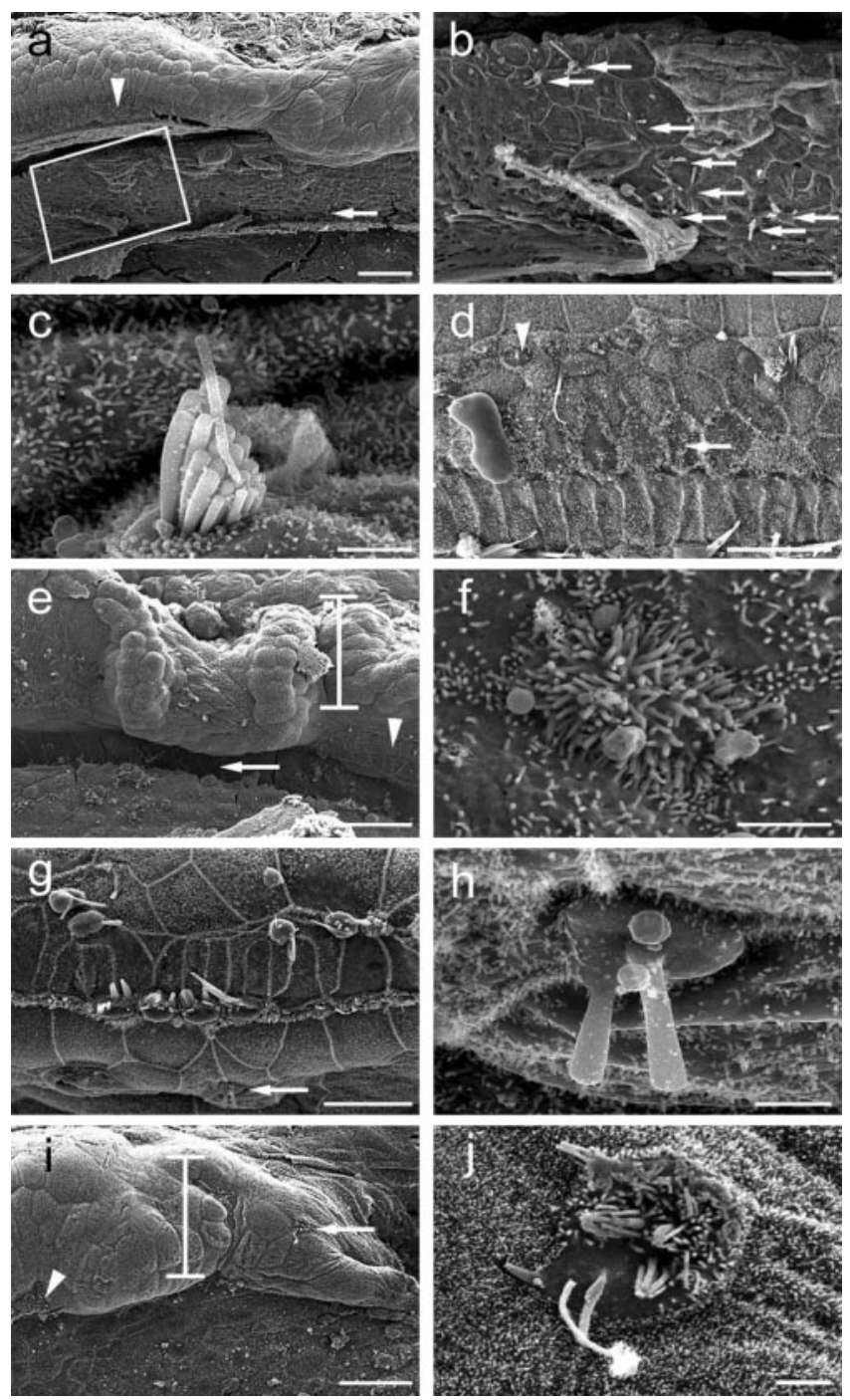

Figure 3. Scanning electron microscopy of cochleae after Ad.Math1.11D treatment. $a, A n$ interdental cell area (boxed) with several ectopic hair cells medial to the organ of Corti (arrowhead). $b$, Box in $a$ enlarged to show ectopic hair cells (arrows). c, Higher magnification of ectopic hair cell in interdental cell area ( $a$, arrow) with a well developed stereocilia bundle. $d$, Inoculation-lesioned organ of Corti exhibits cells with short stereocilia (arrow) and small hair cells (arrowhead). Micrographs are oriented with medial (modiolar) side down. $e$, The site of inoculation showing the injured organ of Corti (arrowhead) and Hensen cells (bar). $f$, An ectopic hair cell with short stereocilia in the inner sulcus (e, arrow). $g$, Hair cells in the organ of Corti distant from the inoculation site are missing or injured. $h$, An ectopic hair cell in the inner sulcus ( $g$, arrow). $i$, Lateral to the organ of Corti (arrowhead), Hensen cells (bar) exhibit an ectopic hair cell (arrow). $j$, Higher magnification of ectopic hair cell depicted in $i$. Micrographs are oriented with medial (modiolar) side down. Scale bars: $a, e, i, 50 \mu \mathrm{m} ; b, d, g, 20 \mu \mathrm{m} ; c, f, h, j, 2 \mu \mathrm{m}$.

out a proliferative mechanism, the occurrence of single ectopic hair cells, rather than pairs, in our study lends support to a conversion mechanism. The developmental role of Math1 as a differentiation factor also supports a conversion mechanism for the regenerative process in the mature animal.

Our data raise several issues regarding the potential for use of Math 1 gene therapy for restoring hearing. First, the inoculation into the endolymph damages the organ of Corti. Candidates for inner ear gene therapy in the future are likely to have preexisting severe hair cell lesions, making the adverse effects of this procedure less troubling. It is also likely that vector inoculation into the larger human cochleae would elicit less mechanical trauma compared with that seen in guinea pigs. Second, in severely trauma-

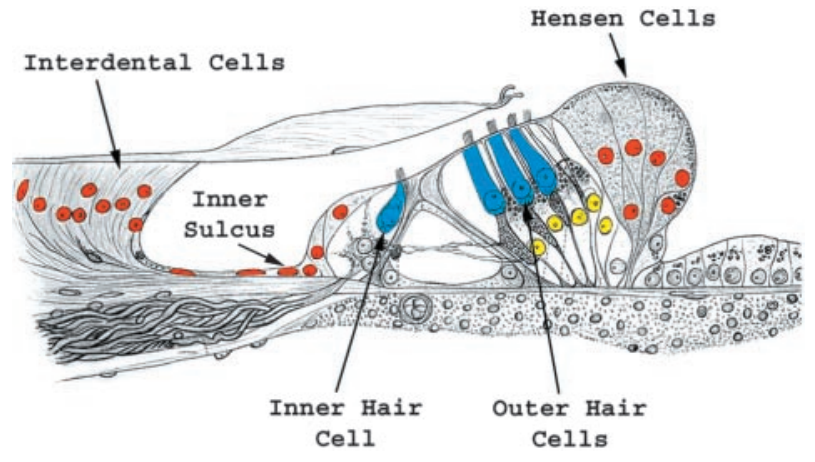

Figure 4. Math1-positive nuclei and ectopic hair cells. The schematic of the organ of Corti is oriented similar to the mid-modiolar cross sections in Figure $1, a$ and $d-g$, in which medial is on left and lateral is on right. The epithelial regions that exhibit Math1-positive nuclei include the organ of Corti (yellow) and ectopic areas adjacent to the organ of Corti (red). Ectopic new hair cells were identified in the interdental cell, inner sulcus, and Hensen cell regions.

tized cochleae, supporting cells often become dedifferentiated and appear like cells in the inner sulcus (Leake and Hradek, 1988), making them candidate precursors for efficient generation of new hair cells.

Innervation of the new hair cells would be a prerequisite for restoring hearing. The ability of new hair cells to receive new nerve terminals has been demonstrated in the regenerating avian basilar papilla (Ofsie and Cotanche, 1996; Wang and Raphael, 1996). Our data showing axonal extension toward new ectopic hair cells suggest that new hair cells can provide signals to attract axons and that neurons can respond to these signals and extend toward the new hair cells. Because some of the ectopic hair cells did not have a neuron in their vicinity at the time points studied in our experiments, we conclude that new hair cells develop independently of neurons, as shown previously during cochlear development (Fritzsch et al., 1999). Longer survival times after Math1 overexpression may be needed to allow more new hair cells to receive axonal connections.

In conclusion, we show that new hair cells are generated after Math1 overexpression via an adenovirus vector in the mature mammalian cochlea. The new hair cells exhibit the typical surface morphology of hair cells and stain for the hair cell-specific protein myosin VIIa. The new hair cells are ectopically positioned and able to attract auditory nerve fibers, raising the possibility that they may be functional. This is the first in vivo induction of new hair cell generation in the mammalian cochlea and the first success in inducing regeneration in any tissue in which spontaneous cell replacement does not occur. The ability to generate hair cells in the mammalian organ of Corti may lead to treatments for sensorineural deafness and the development of methods for inducing regeneration and innervation in other organs.

\section{References}

Adler HJ, Raphael Y (1996) New hair cells arise from supporting cell conversion in the acoustically damaged chick inner ear. Neurosci Lett 205:17-20.

Bermingham NA, Hassan BA, Price SD, Vollrath MA, Ben-Arie N, Eatock RA, Bellen HJ, Lysakowski A, Zoghbi HY (1999) Math1: an essential gene for the generation of inner ear hair cells. Science 284:1837-1841.

Brough DE, Lizonova A, Hsu C, Kulesa VA, Kovesdi I (1996) A gene transfer vector-cell line system for complete functional complementation of adenovirus early regions E1 and E4. J Virol 70:6497-7501.

Brown NL, Kanekar S, Vetter ML, Tucker PK, Gemza DL, Glaser T (1998) Math5 encodes a murine basic helix-loop-helix transcription factor expressed during early stages of retinal neurogenesis. Development 125:4821-4833. 
Chen P, Johnson JE, Zoghbi HY, Segil N (2002) The role of Math1 in inner ear development: Uncoupling the establishment of the sensory primordium from hair cell fate determination. Development 129:2495-2505.

Corwin JT, Cotanche DA (1988) Regeneration of sensory hair cells after acoustic trauma. Science 240:1772-1774.

Erkman L, McEvilly RJ, Luo L, Ryan AK, Hooshmand F, O'Connell SM, Keithley EM, Rapaport DH, Ryan AF, Rosenfeld MG (1996) Role of transcription factors Brn-3.1 and Brn-3.2 in auditory and visual system development. Nature 381:603-606.

Fritzsch B, Pirvola U, Ylikoski J (1999) Making and breaking the innervation of the ear: neurotrophic support during ear development and its clinical implications. Cell Tissue Res 295:369-382.

Hasson T, Heintzelman MB, Santos-Sacchi J, Corey DP, Mooseker MS (1995) Expression in cochlea and retina of myosin VIIa, the gene product defective in Usher syndrome type 1B. Proc Natl Acad Sci USA 92:9815-9819.

Hawkins Jr JE (1973) Comparative otopathology: aging, noise, and ototoxic drugs. Adv Otorhinolaryngol 20:125-141.

Hutcheson DA, Vetter ML (2001) The bHLH factors Xath5 and XNeuroD can upregulate the expression of XBrn3d, a POU-homeodomain transcription factor. Dev Biol 232:327-338.

Ishimoto S, Kawamoto K, Kanzaki S, Raphael Y (2002) Gene transfer into supporting cells of the organ of Corti. Hear Res 173:187-197.

Leake PA, Hradek GT (1988) Cochlear pathology of long term neomycin induced deafness in cats. Hear Res 33:11-33.

Leonard JH, Cook AL, Van Gele M, Boyle GM, Inglis KJ, Speleman F, Sturm RA (2002) Proneural and proneuroendocrine transcription factor expression in cutaneous mechanoreceptor (Merkel) cells and Merkel cell carcinoma. Int J Cancer 101:103-110.

Ofsie MS, Cotanche DA (1996) Distribution of nerve fibers in the basilar papilla of normal and sound-damaged chick cochleae. J Comp Neurol 370:281-294.

Osborne MP, Comis SD (1991) Preparation of inner ear sensory hair bundles for high resolution scanning electron microscopy. Scanning Microsc 5:555-564.

Raphael Y (1992) Evidence for supporting cell mitosis in response to acoustic trauma in the avian inner ear. J Neurocytol 21:663-671.
Roberson DW, Kreig CS, Rubel EW (1996) Light microscopic evidence that direct transdifferentiation gives rise to new hair cells in regenerating avian auditory epithelium. Aud Neurosci 2:195-205.

Ryals BM, Rubel EW (1988) Hair cell regeneration after acoustic trauma in adult Coturnix quail. Science 240:1774-1776.

Slepecky NB (1996) Cochlear structure. In: The cochlea (Dallos P, Popper AN, Fay R, eds), pp 44-129. New York: Springer.

Stone JS, Cotanche DA (1994) Identification of the timing of S phase and the patterns of cell proliferation during hair cell regeneration in the chick cochlea. J Comp Neurol 341:50-67.

Stone JS, Rubel EW (2000) Cellular studies of auditory hair cell regeneration in birds. Proc Natl Acad Sci USA 97:11714-11721.

Strominger RN, Bohne BA, Harding GW (1995) Regenerated nerve fibers in the noise-damaged chinchilla cochlea are not efferent. Hear Res 92:52-62.

Thorne M, Salt AN, DeMott JE, Henson MM, Henson Jr OW, Gewalt SL (1999) Cochlear fluid space dimensions for six species derived from reconstructions of three-dimensional magnetic resonance images. Laryngoscope 109:1661-1668.

Vahava O, Morell R, Lynch ED, Weiss S, Kagan ME, Ahituv N, Morrow JE, Lee MK, Skvorak AB, Morton CC, Blumenfeld A, Frydman M, Friedman TB, King MC, Avraham KB (1998) Mutation in transcription factor POU4F3 associated with inherited progressive hearing loss in humans. Science 279:1950-1954.

Vetter ML, Brown NL (2001) The role of basic helix-loop-helix genes in vertebrate retinogenesis. Semin Cell Dev Biol 12:491-498.

Wang Y, Raphael Y (1996) Re-innervation patterns of chick auditory sensory epithelium after acoustic overstimulation. Hear Res 97:11-18.

Zheng JL, Gao WQ (2000) Overexpression of Math1 induces robust production of extra hair cells in postnatal rat inner ears. Nat Neurosci 3:580-586.

Zheng JL, Shou J, Guillemot F, Kageyama R, Gao WQ (2000) Hes1 is a negative regulator of inner ear hair cell differentiation. Development 127:4551-4560.

Zine A, Aubert A, Qiu J, Therianos S, Guillemot F, Kageyama R, de Ribaupierre F (2001) Hes1 and Hes5 activities are required for the normal development of the hair cells in the mammalian inner ear. J Neurosci 21: 4712-4720. 